\title{
Voltammetric Analysis of Montelukast Sodium in Commercial Tablet and Biological Samples Using the Hanging Mercury Drop Electrode
}

\author{
Ali F. Alghamdi* \\ Department of Chemistry, College of Science, Taibah University \\ P.O. Box 30002, Madinah, Saudi Arabia
}

Received 23 January 2014; accepted 25 February 2014

\begin{abstract}
Adsorptive stripping voltammetry was used to prospect the adsorption property of montelukast sodium (MKST) on the hanging mercury drop electrode (HMDE). Through appointing the adsorptive stripping voltammetric (AdSV) process, a sensitive electroanalytical method for the quantitative analysis of MKST was accomplished. A well-developed voltammetric peak was obtained in $\mathrm{pH} 10$ Britton-Robinson buffer (B-R buffer) at $-1.080 \mathrm{~V}$. The cyclic voltammetric studies indicated that the reduction process was irreversible and primarily controlled by adsorption phenomena. The studies of the variation of adsorptive voltammetric peak current with buffer electrolyte, $\mathrm{pH}$, accumulation time $\left(\mathrm{t}_{\mathrm{acc}}\right)$, accumulation potential $\left(\mathrm{E}_{\mathrm{acc}}\right)$, sweep rate, pulse amplitude, square wave frequency, working electrode area and convection rate have evaluated in the recognition of optimal experimental conditions for MKST analysis. The studied electroanalytical signal showed a linear response for MKST in the concentration range $5 \times 10^{-8}-1 \times 10^{-6} \mathrm{~mol} \mathrm{~L}^{-1}(\mathrm{r}=0.994)$. A detection limit of $4 \times 10^{-9} \mathrm{~mol} \mathrm{~L}^{-1}$ with relative standard deviation of $1.1 \mathrm{RSD} \%$ and mean recovery of $102 \% \pm 2.0$ were obtained. The possible interferences by several compounds usually present in the pharmaceutical formulation were also evaluated. The analytical quantification of MKST drug in commercially available pharmaceutical formulation and biological samples was electrochemically studied.
\end{abstract}

Keywords: adsorptive stripping voltammetry, cyclic voltammetry, montelukast sodium, hanging mercury drop electrode, pharmaceutical formulation.

\section{Introduction}

Generally, electrochemical techniques that measure or monitor the current flow between a pair of electrodes utilize the electrolyte cell concept. This current is proportional to the concentration of the analyte in the solution. Voltammetric

\footnotetext{
* Corresponding author. E-mail address: alifh2006@ hotmail.com
} 
methods measure the current that flows as the applied potential is varied [1]. Adsorptive stripping voltammetry (AdSV) method has been well characterized as an extremely sensitive source for electroanalytical measurements since its establishment half a century ago. Such electrochemical approach with improved sensitivity and selectivity have promoted the development of numerous analytical applications of ultra-trace determinations of a variety of organic or inorganic substances. AdSV method involves a stripping step carried out by using a square wave time-potential waveform imposed on the working electrode. The principle advantages of AdSV over other stripping techniques (namely differential pulse, linear sweep and so forth) are its enhanced powers of detection, velocity of analysis and sensitivity of dissolved oxygen in the analysed samples [2-4].

Cyclic voltammetry belongs to the category of voltammetric techniques based on a linear potential sweep chronoamperometric techniques. It certainly constitutes the most useful technique for a preliminary determination of the redox properties of a given species [5].

There have been many reviews devoted to emphasize and illustrate the wide spectrum and scope of AdSV applications and potentialities in the analysis of metal ions [6-10], food analysis [11], organic analytes [12,13] and pharmaceutical drugs and biomedical compounds [14-25].

Montelukast (trade names Singulair and Montelo-10) is a leukotriene receptor antagonist (LTRA) used for the maintenance treatment of asthma and to relieve symptoms of seasonal allergies. It is used for a number of conditions such as: asthma, exercise induced bronchospasm, allergic rhinitis, and urticaria. Its discovery had a significant impact on treatment strategies for the management of asthma. It is mainly used as a complementary therapy in adults in addition to inhaled corticosteroids, if they alone don't bring the desired influence. Corticosteroids lessen inflammation but have no effect on the leukotrienes. Mountelukast sodium is described chemically as [R-(E)]-1-[[[1-[3-[2-(7-chloro2quinolinyl)ethenyl]phenyl]-3-[2-(1-hydroxy-1-methylethyl) phenyl] propyl] thio] methyl] cyclo propane acetic acid, mono-sodium salt. The chemical formula of MKST is $\mathrm{C}_{35} \mathrm{H}_{35} \mathrm{ClNNaO}_{3} \mathrm{~S}$, and its molecular weight is 608.18 [26-29]. The structural formula of this analysed pharmaceutical compound is exhibited in scheme 1.

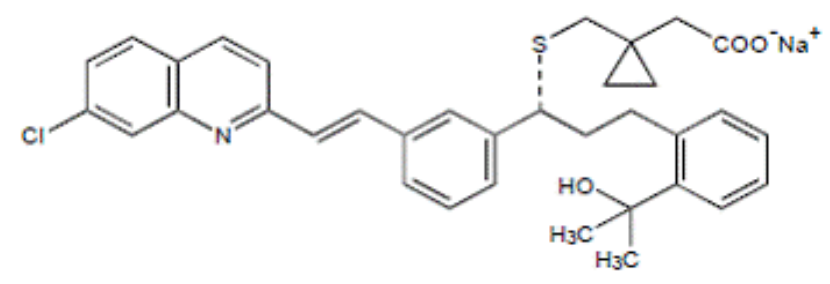

Scheme 1. Chemical formula of montelukast sodium (MKST).

MKST has been analyzed in pharmaceutical formulations and biological samples by various analytical methods such as spectrophotometry [30,31], high performance liquid chromatography (HPLC) [32,33] and electrochemical methods such as polarography and differential pulse voltammetry [34]. However, no literature data were found on the square wave - adsorptive stripping voltammetry in general and of this drug in particular. Consequently, the 
development of SW-AdSV method for the analysis of MKST, and its application to determination in pharmaceutical formulations and biological fluids, is described.

\section{Experimental \\ Apparatus}

All electrochemical measurements were carried out with a 797 VA (Metrohm, Switzerland) connected with Dell computer and controlled by (VA computrace 2.0) control software. The stripping voltammograms were printed via a hp color laserjet CP1215 printer. A conventional three electrode system was used in the hanging mercury drop electrode (HMDE) mode. The $\mathrm{pH}$ values were measured with a Hanna instruments pH211 (Romania made). Oxford adjustable micropipette (Ireland) was used to measure microliter volumes of the standard solutions. The labofuge 200 instrument, Heraeus sepatech (German made) was used to centrifuge the biological fluids to be suited for stripping analysis.

\section{Reagents}

Montelukast sodium stock solution (Qassim Pharmaceutical Plant, Buraydah, Spimaco Addwaeih, Saudi Arabia) of $1 \times 10^{-3} \mathrm{~mol} \mathrm{~L}^{-1}$ was prepared by dissolving the appropriate amount of MKST in distilled water in a $50 \mathrm{~mL}$ volumetric flask and this stock solution was stored in the dark. Britton-Robinson supporting buffer ( $\mathrm{pH} \approx 2,0.04 \mathrm{M}$ in each constituent) was prepared by dissolving $2.47 \mathrm{~g}$ of boric acid (winlab, UK) in $500 \mathrm{~mL}$ distilled water containing $2.3 \mathrm{~mL}$ of acetic acid (BDH, UK), then adding $2.7 \mathrm{~mL}$ of phosphoric acid (Riedal-deHaen, Germany) and diluting to $1000 \mathrm{~mL}$ with distilled water. In addition, phosphate buffer $\left[0.1 \mathrm{M} \mathrm{NaH} \mathrm{PO}_{4}\right.$ (winlab, UK) and $\left.0.1 \mathrm{M} \mathrm{H}_{3} \mathrm{PO}_{4}\right]$ was prepared by dissolving $12 \mathrm{~g}$ of $\mathrm{NaH}_{2} \mathrm{PO}_{4}$ and $6.78 \mathrm{~g}$ of $\mathrm{H}_{3} \mathrm{PO}_{4}$ in $1000 \mathrm{~mL} \mathrm{H} \mathrm{H}_{2} \mathrm{O}$. Acetate buffer ( $0.02 \mathrm{M}$ in each constituent) was prepared by dissolving $1.68 \mathrm{~g}$ of sodium acetate $(\mathrm{BDH}, \mathrm{UK})$ in $500 \mathrm{~mL} \mathrm{H}_{2} \mathrm{O}$ containing $1.12 \mathrm{~mL}$ of acetic acid and diluting to $1000 \mathrm{~mL}$ with $\mathrm{H}_{2} \mathrm{O}$. While, carbonate buffer $(0.1 \mathrm{M}$ in each constituent) was prepared by dissolving $10.6 \mathrm{~g}$ of sodium carbonate (winlab, UK) and $8.4 \mathrm{~g}$ of sodium hydrogen carbonate (winlab,UK) in $1000 \mathrm{~mL}$ distilled water.

\section{Procedure}

The general procedure adopted for getting adsorptive stripping voltammograms was as follows: a $10 \mathrm{~mL}$ of B-R supporting electrolyte at desired $\mathrm{pH}$ was pipetted in a clean and dry electrochemical cell and the required standard solutions of MKST were added. The test solutions were purged with nitrogen for 5 minutes initially, while the solution was stirred. The accumulation potential of $-0.4 \mathrm{~V}$ vs. $\mathrm{Ag} / \mathrm{AgCl}$ was applied to a new mercury drop while the solution was stirred for 180 seconds. Following the preconcentration period, the stripping was stopped and after 10 seconds had elapsed, and cathodic scans were carried out over the range 0.0 to $-1.3 \mathrm{~V}$. All measurements were carried out at room temperature. 


\section{Application to tablets}

The tablet solution was prepared by use five tablets weighed accurately and finely powdered and mixed. The tablets were given stock solution of MKST $\left(1 \times 10^{-3} \mathrm{molL}^{-1}\right)$ in $50 \mathrm{~mL}$ of $\mathrm{MeOH}$ by use volumetric flask. The content of the flask was left in the room temperature and the dark for $48 \mathrm{~h}$ to provide dissolution and then completed to forthwith determine MKST compound by use of the standard additions method.

\section{Application to biological fluids}

Regarding human urine and plasma preparations, $1.0 \mathrm{~mL}$ of $5 \% \mathrm{ZnSO}_{4} .7 \mathrm{H}_{2} \mathrm{O}$ solution, $0.1 \mathrm{~mL}$ of $\mathrm{NaOH}$ and $1.0 \mathrm{~mL}$ of ethanol were added to $0.5 \mathrm{~mL}$ of human urine and plasma samples and $3 \times 10^{-7} \mathrm{molL}^{-1}$ MKST drug [35]. This solution was centrifuged for $15 \mathrm{~min}$ at $4000 \mathrm{rpm}$ to separate out the insoluble excipients. Thereafter, the solution was taken and diluted B-R buffer at $\mathrm{pH} 10$ to achieve the desired concentration. Then the procedure was completed by use standard additions method.

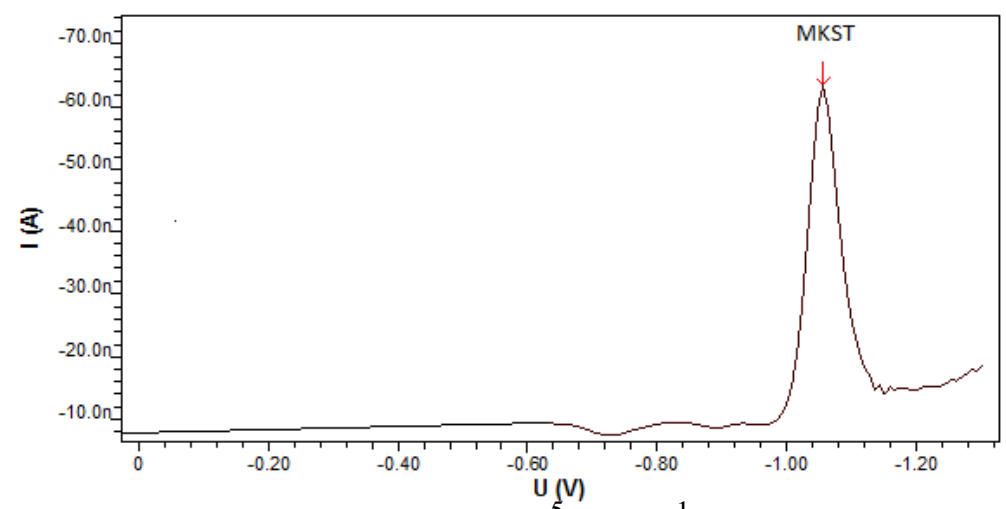

Figure 1. Electrochemical behaviour of $1 \times 10^{-5} \mathrm{molL}^{-1} \mathrm{MKST}$ in $\mathrm{pH} 10 \mathrm{~B}-\mathrm{R}$ buffer, by use DPP.

\section{Results and discussion}

\section{The electroanalytical properties of MKST}

The preliminary voltammetric study of MKST pharmaceutical molecule indicates that it has cathodic reduction response onto the HMDE electrode by using differential pulse polarographic (DPP) approach and using an applied potential in the negative direction. $1 \times 10^{-5} \mathrm{~mol} \mathrm{~L}^{-1}$ of MKST in $\mathrm{pH} 10$ Britton-Robinson buffer was given a reduction polarographic peak, as can be seen from Fig. 1. Fig. 2 exhibited a stripping reduction voltammogram for $5 \times 10^{-7} \mathrm{~mol} \mathrm{~L}^{-1} \mathrm{MKST}$ in $\mathrm{pH}$ $10 \mathrm{~B}-\mathrm{R}$ buffer by using square wave voltammetric technique. However, the addition of $5 \times 10^{-7} \mathrm{~mol} \mathrm{~L}^{-1}$ MKST to the test solution provided a well-defined cathodic peak at - $1080 \mathrm{mV}$ (versus $\mathrm{Ag} / \mathrm{AgCl}$ reference electrode). The observed AdSV peak is most probably due to the cathodic reduction of the double bond $(\mathrm{C}=\mathrm{C})$ to single bond $(\mathrm{C}-\mathrm{C})$ in the sub-strain of adsorbed drug and the electrochemical mechanism of this reduction process for MKST is illustrated in scheme 2 . 


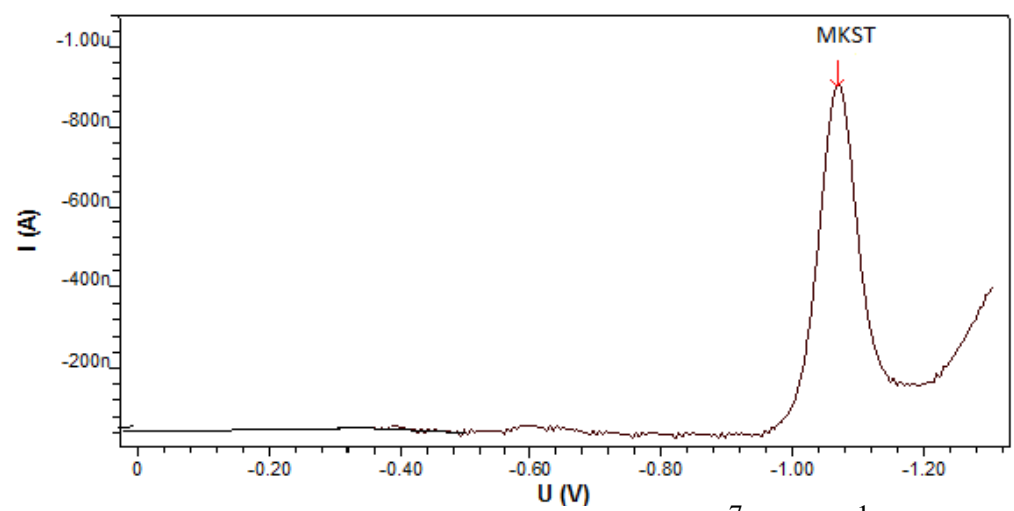

Figure 2. Adsorptive stripping voltammogram of $5 \times 10^{-7}$ molL $^{-1}$ MKST in pH 10 B-R buffer.

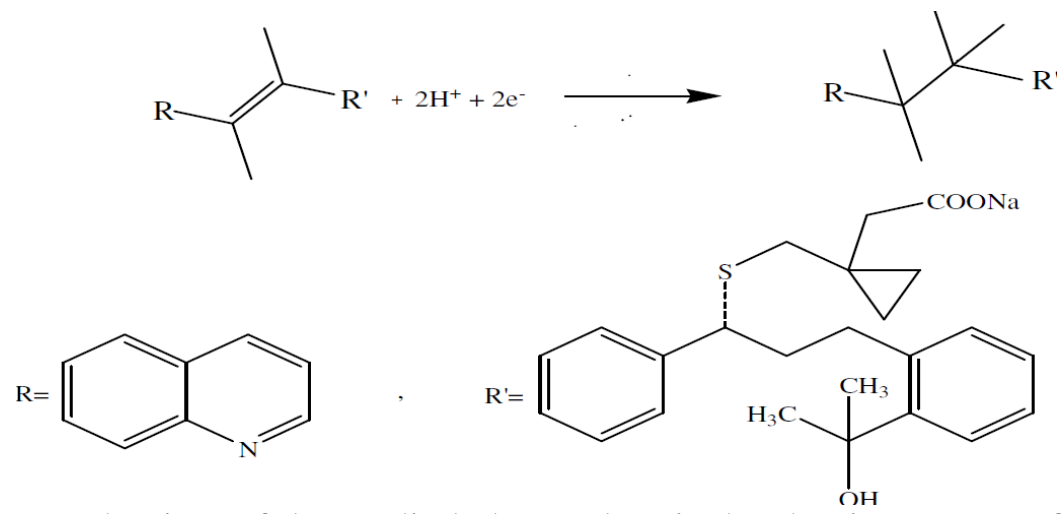

Scheme 2. Mechanism of the studied electrochemical reduction process for MKST.

Obviously, this proposed electrochemical reduction mechanism suggested an irreversible reductive process for the adsorbed drug, an assumption which was confirmed by cyclic voltammetric measurement of $1 \times 10^{-5} \mathrm{~mol} \mathrm{~L}^{-1} \mathrm{MKST}$ drug in pH 10 B-R buffer at $100 \mathrm{mVs}^{-1}$ scan rate. As can be noticed from Fig. 3, which exhibits the cyclic voltammogram of MKST, the absence of the anodic peak at the reverse scan confirmed the irreversible nature of the evaluated reduction process. Furthermore, when repetitive cyclic voltammetric measurements for MKST drug were carried out as shown in Fig. 4, a well developed CV peak was observed at the first cathodic scan; however, succeeding cathodic scans exhibit a gradual decrease in the voltammetric peak intensity that seemed to indicate the adsorptive characteristic of this compound at the surface of the employed working electrode.

Anyway, the interfacial accumulation of this drug onto the HMDE surface can be used as an effective accumulation step in order to enhance the electroanalytical determination of MKST molecules. On the other hand, the linear enhancements between the electroanalytical signals and different values of scan rate were studied using cyclic voltammetry technique over the range 10-120 mV/s. So, a linear relationship of $\log (\mathrm{I})$ vs. $\log (\mathrm{v})$ was illustrated, as shown in Fig. 5, which yielded a slope of 0.9 that is close to 1.00 value indicating that electrochemical reduction of MKST at the working electrode (HMDE) is an adsorptioncontrolled process [36]. In addition, a shift to more negative potential was observed upon increasing the scan rate, which confirms the irreversibility of the electroanalytical reduction of MKST. 




Figure 3. Cyclic voltammogram for $1 \times 10^{-5} \mathrm{~mol} \mathrm{~L}^{-1} \mathrm{MKST}$ in $\mathrm{pH} 10 \mathrm{~B}-\mathrm{R}$ buffer at 100 $\mathrm{mVs}^{-1}$ scan rate.

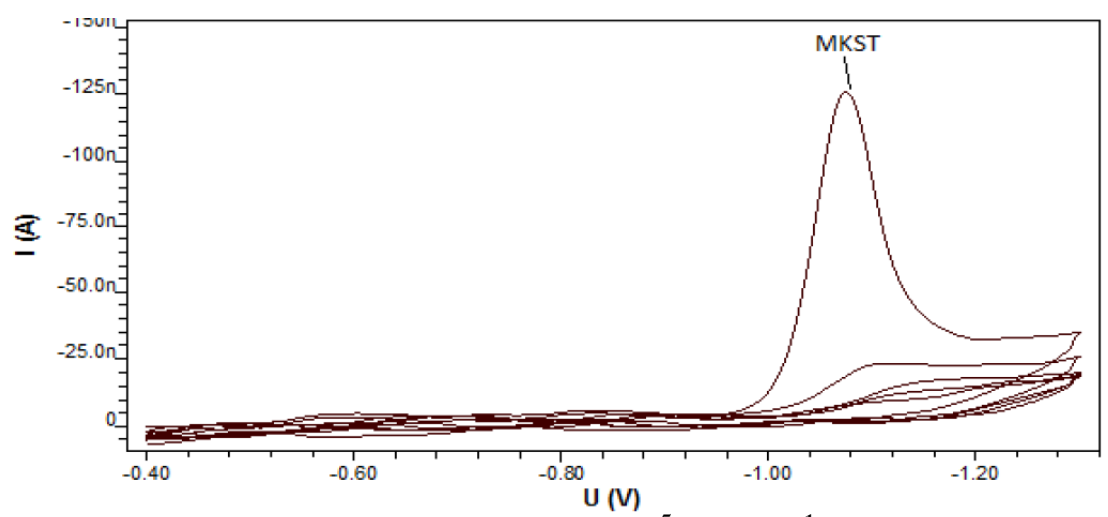

Figure 4. Multi-cyclic voltammograms for $1 \times 10^{-5} \mathrm{~mol} \mathrm{~L}^{-1}$ MKST in $\mathrm{pH} 10 \mathrm{~B}-\mathrm{R}$ buffer at $100 \mathrm{mVs}^{-1}$ scan rate.

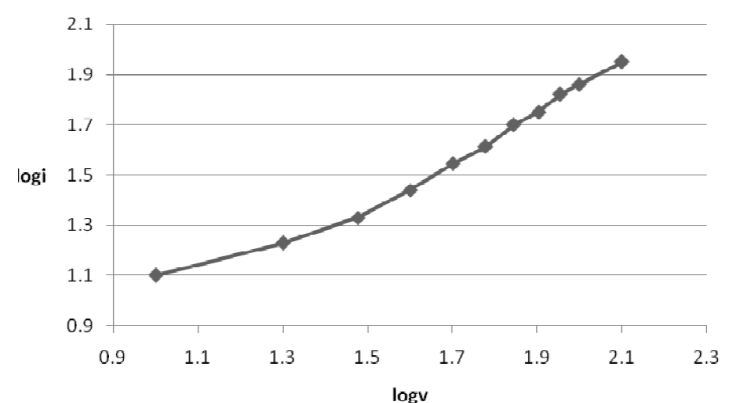

Figure 5. The relationship of $\log (\mathrm{I})$ vs. $\log (v)$ using cyclic voltammetry technique at different scan rate values for $1 \times 10^{-5} \mathrm{~mol} \mathrm{~L}^{-1}$ MKST in $\mathrm{pH} 10 \mathrm{~B}-\mathrm{R}$ buffer.

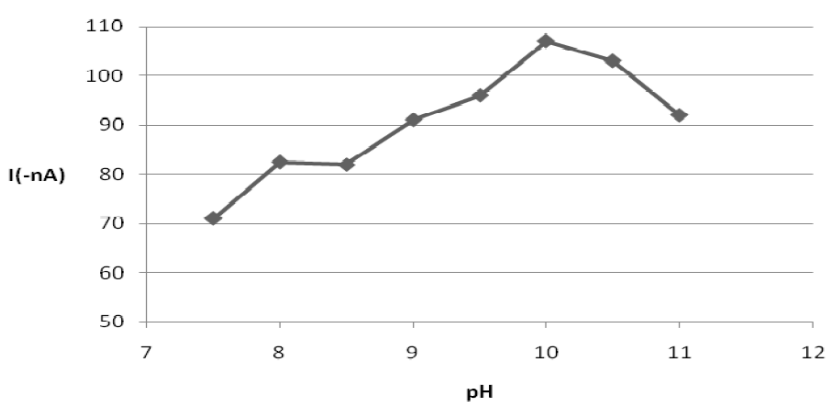

Figure 6. Effect of $\mathrm{pH}$ on AdSV peak current of $5 \times 10^{-7} \mathrm{~mol} \mathrm{~L}^{-1} \mathrm{MKST}$ in B-R buffer. 


\section{Optimisation of experimental parameters}

Effect of supporting buffer constituents and $\mathrm{pH}$

Since the adsorptive phenomenon of MKST on the working electrode (HMDE) was utilized as a suitable collection step prior to its electrochemical analysis, it was rational to characterize various variables and experimental conditions affecting the engaged adsorption procedure. Actually, the sensitivity of the adsorptive stripping process for a particular analyte is usually significantly influenced by the composition of the electrolyte buffer and $\mathrm{pH}$ values. Consequently, many electrolyte buffers such as: Britton-Robinson (B-R), acitae, carbonate and phosphate buffers at different $\mathrm{pH}$ values were evaluated after 60 sec $t_{a c c}$ at $0.0 \quad \mathrm{~V} \quad E_{a c c}$. Amongst these supporting electrolytes the best electroanalytical signal in terms of AdSV peak current intensity and shape was obtained with B-R buffer, which was selected as optimal for further works.

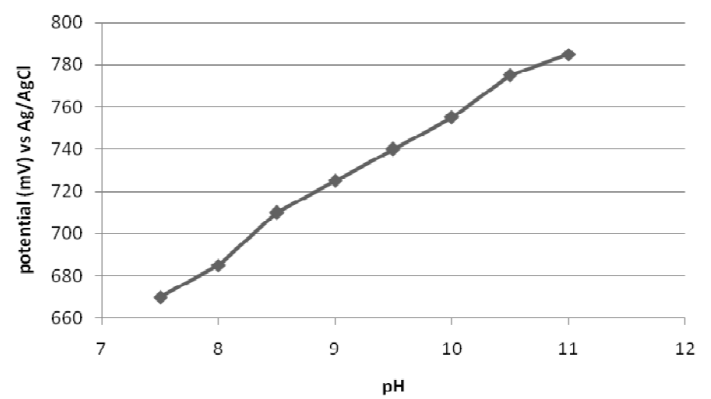

Figure 7. The relationship between $\mathrm{pH}$ and potential using SWV technique for $5 \times 10^{-7}$ mol L ${ }^{-1}$ MKST in $\mathrm{pH} 10 \mathrm{~B}-\mathrm{R}$ buffer.

Generally, the AdSV signal was mainly $\mathrm{pH}$ dependent since the monitored voltammetric signal was only observed at alkaline state. When the voltammetric peak signal was measured as a function of $\mathrm{pH}$ over the range 7.5-11, the peak current increased gradually at first and enhanced sharply beyond $\mathrm{pH} 8.5$, then it reached its maximum value at $\mathrm{pH} 10$, which was adopted as the optimum $\mathrm{pH}$ value for subsequent investigations. The influence of $\mathrm{pH}$ factor on the AdSV signal is illustrated in Fig. 6. On the other hand, it is observed that the peak potential was shifted gradually to more negative values from $-670 \mathrm{mV}$ to -785 $\mathrm{mV}$ upon increasing $\mathrm{pH}$ over the range 7.5-11, (see Fig. 7). From the plot of Ep vs. $\mathrm{pH}$, slope value of $33 \mathrm{mV} / \mathrm{pH}$ was recorded, that is close to the expected theoretical value of $30 \mathrm{mV} / \mathrm{pH}$. Interestingly, this result indicates that $\mathrm{E}_{\mathrm{p}}$ is $\mathrm{pH}$ dependent as expected for the electroanalytical reduction process; yield, the proposed electrochemical mechanism consumes two protons [37] for the voltammetric determination of MKST.

\section{Effect of accumulation factors}

The interfacial accumulation of MKST onto the HMDE surface depends on some factors, which added importance investigations in order to obtain high sensitive determinations for MKST drug. Therefore, the effect of accumulation time on the efficiency of the collection of $5 \times 10^{-7} \mathrm{~mol} \mathrm{~L}^{-1}$ MKST onto the working electrode was evaluated by rising the accumulation time over the range $0-220 \mathrm{sec}$. The 
resulting peak current-accumulation time $\left(i_{p}-t_{a c c}\right)$ profile is exhibited in Fig. 8 and as can be seen from this plot, an enhancement in the voltammetric peak current was observed over the range $0-180 \mathrm{sec}$. After this range, the peak intensity didn't change almost because of probably saturation of the mercury electrode. Hence, $180 \mathrm{sec}$ accumulation time was selected for all additional experiments. On the other hand, variation of the accumulation potentials over the range from $+0.6 \mathrm{~V}$ to $-1.0 \mathrm{~V}$ at $180 \mathrm{sec}$ accumulation time, as shown in Fig. 9, revealed that a preconcentration potential of $-0.4 \mathrm{~V}$ was the ideal choice for optimal sensitivity.

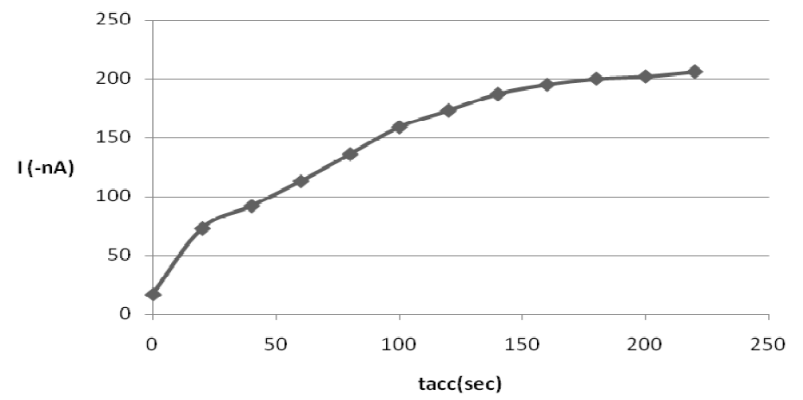

Figure 8. Effect of accumulation time on the stripping voltammetric peak current of $5 \times 10^{-7} \mathrm{~mol} \mathrm{~L}^{-1}$ MKST in $\mathrm{pH} 10 \mathrm{~B}-\mathrm{R}$ buffer.

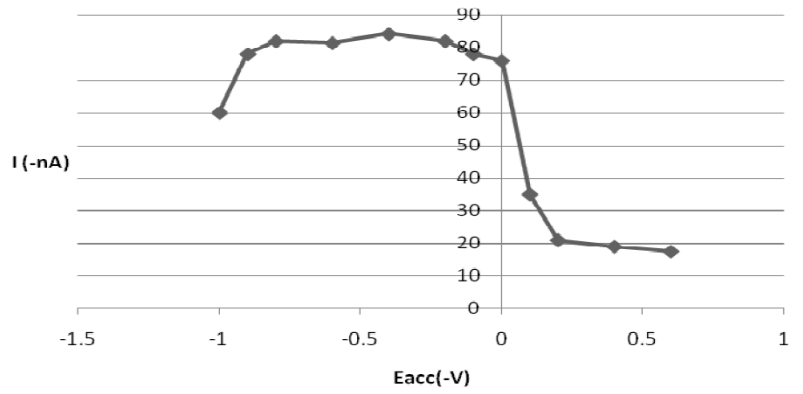

Figure 9. Effect of accumulation potential on the stripping voltammetric peak current of $5 \times 10^{-7} \mathrm{~mol} \mathrm{~L}^{-1} \mathrm{MKST}$ in $\mathrm{pH} 10 \mathrm{~B}-\mathrm{R}$ buffer; accumulation time: $180 \mathrm{~s}$.

\section{Effect of potential sweep parameters}

The observed stripping voltammetric signal can be further maximized by adjusting the way the applied potential was monitored. The relationship between the peak intensity and scan rate was found to be directly proportional over 50$750 \mathrm{mV} \mathrm{s}^{-1}$ scan rate. However, when scan rate faster than $650 \mathrm{mV} \mathrm{s}^{-1}$ were used, the current decreased slightly. The effect of scan rate on the observed voltammetric signal is illustrated in Fig. 10, which indicates that scan rate value of $650 \mathrm{mV} \mathrm{s}^{-1}$ would be adequate optimum for succeeding investigations.

In addition, the impact of varying the excitation wave pulse amplitude on the voltammetric current intensity was evaluated. The effect of pulse amplitude was studied over the range $10-100 \mathrm{mV}$ (see Fig. 11) and it was concluded that in order to assure maximum peak current, $50 \mathrm{mV}$ pulse amplitude is the ideal choice for operational parameters. In addition, varying the value of square wave frequency also plays an important role for the measured signal of AdSV approach. 


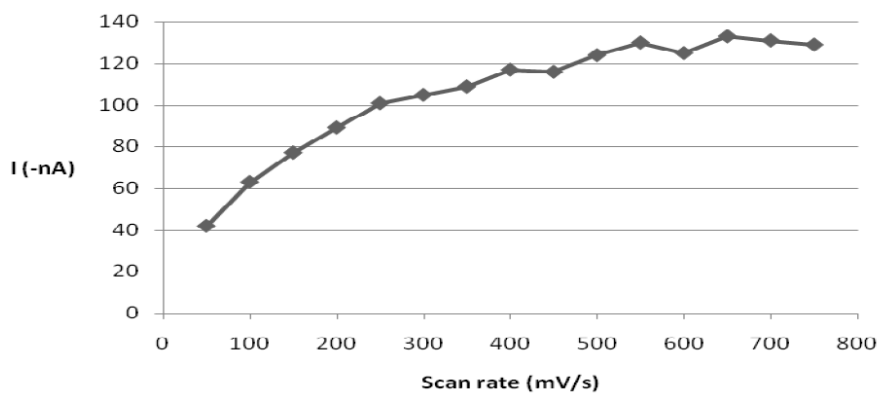

Figure 10. Effect of scan rate on AdSV peak current of $5 \times 10^{-7} \mathrm{~mol} \mathrm{~L}^{-1} \mathrm{MKST}$ in $\mathrm{pH} 10$ B-R buffer. Accumulation time: $180 \mathrm{sec}$ and accumulation potential: $-0.4 \mathrm{~V}$.

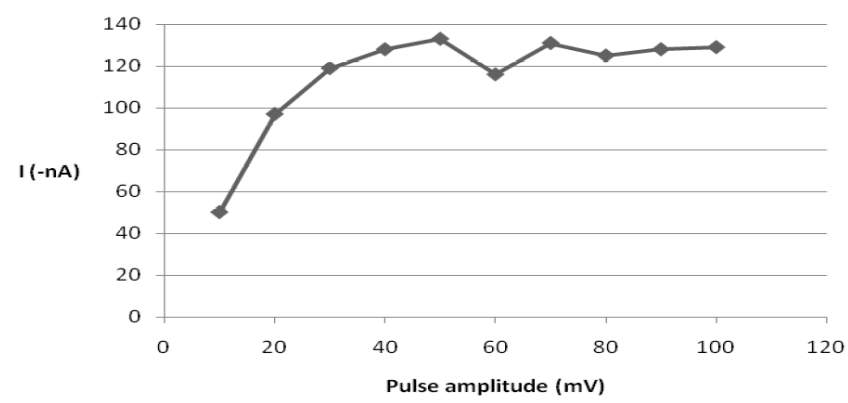

Figure 11. Effect of pulse amplitude on the stripping voltammetric peak current of $5 \times 10^{-7}$ mol L ${ }^{-1}$ MKST in $\mathrm{pH} 10 \mathrm{~B}-\mathrm{R}$ buffer. Accumulation time: $180 \mathrm{sec}$, accumulation potential: $-0.4 \mathrm{~V}$ and scan rate: $650 \mathrm{mV} \mathrm{s}^{-1}$.

Varying this parameter over the range 10-150 Hz resulted in a substantial enhancement of the voltammetric peak current, particularly at range 10-130 Hz, as can be seen from Fig. 12. Accordingly, for future work $130 \mathrm{~Hz} \mathrm{SW}$ frequency value was adopted.

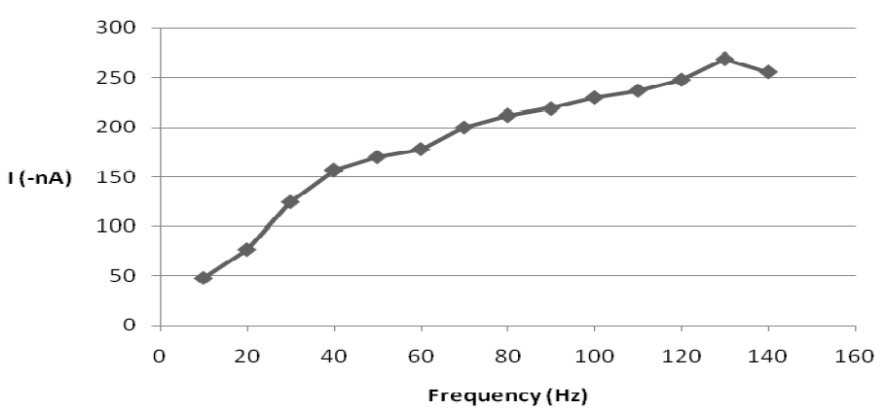

Figure 12. Effect of frequency on the stripping voltammetric peak current of $5 \times 10^{-7}$ molL $^{-1}$ in $\mathrm{pH} 10 \mathrm{~B}-\mathrm{R}$ buffer. Accumulation time: $180 \mathrm{sec}$, accumulation potential: -0.4 $\mathrm{V}$ and scan rate: $650 \mathrm{mV} \mathrm{s}^{-1}, 50 \mathrm{mV}$ pulse amplitude.

\section{Effect of other instrumental variables}

The influence of other operating parameters such as the size of the adsorption area (HMDE) and convection rate on the efficiency of the adsorption accumulation of MKST was also checked. As expected, a linear enhancement relationship for the electrochemical peak intensity was observed when the surface area of HMDE was increased over the range $0.15-0.6 \mathrm{~mm}^{2}$ drop size area. Besides, the AdSV peak current can be maximized further by increasing the 
stirring rate of the rotating rod over the range 0-3000 rpm. Hence, for optimal sensitivity, $0.6 \mathrm{~mm}^{2}$ and $3000 \mathrm{rpm}$ were selected.

In conclusion, for electroanalytical purposes, the optimised experimental conditions for AdSV measurements of MKST drug were accumulating for 180 $\mathrm{sec}$ at $-0.4 \mathrm{~V}$ accumulation potential with stirring rate of $3000 \mathrm{rpm}$. These voltammetric measurements were carried out in Britton-Robinson buffer at $\mathrm{pH}$ 10. The applied potential was scanned at $650 \mathrm{mV} \mathrm{s}^{-1}$ with $130 \mathrm{~Hz} \mathrm{SW}$ frequency rate and $50 \mathrm{mV}$ pulse amplitude.

\section{Analytical performance}

\section{Calibration graph and detection limit}

Once the optimal chemical conditions and instrumental parameters for the AdSV determination of MKST were decided, several analytical properties of the proposed were evaluated. Under the optimised conditions, a linear correlation between AdSV peak intensity and the drug concentration was obtained over the range $5 \times 10^{-8}-1 \times 10^{-6} \mathrm{~mol} \mathrm{~L}^{-1}$, (see Fig. 13). The calibration equation was calculated by least-squares method and it has the form:

$\mathrm{I}_{\mathrm{p}}(\mathrm{nA})=7.7 \times 10^{8} \mathrm{C}\left(\mathrm{mol} \mathrm{l}^{-1}\right)+167.4 \quad \mathrm{r}=0.994, \quad \mathrm{n}=7$

where $I_{p}$ is the stripping voltammetric peak current in nano-amperes, $C$ is MKST concentration, $\mathrm{r}$ is the correlation coefficient and $\mathrm{n}$ is number of measurements. The effective preconcentration step during the adsorption process of the analyzed drug allows a very low detectability. The detection limit estimated based on the signal-to-noise ratio $(\mathrm{S} / \mathrm{N}=3)$ was $4 \times 10^{-9} \mathrm{~mol} \mathrm{~L}^{-1}$. This obtained sensitivity was significantly preferable than those reported for other analytical techniques currently used for determination of MKST drug, such as differential pulse polarography (DPP) with $3.41 \times 0^{-7} \mathrm{M}$ [34] detection limit.

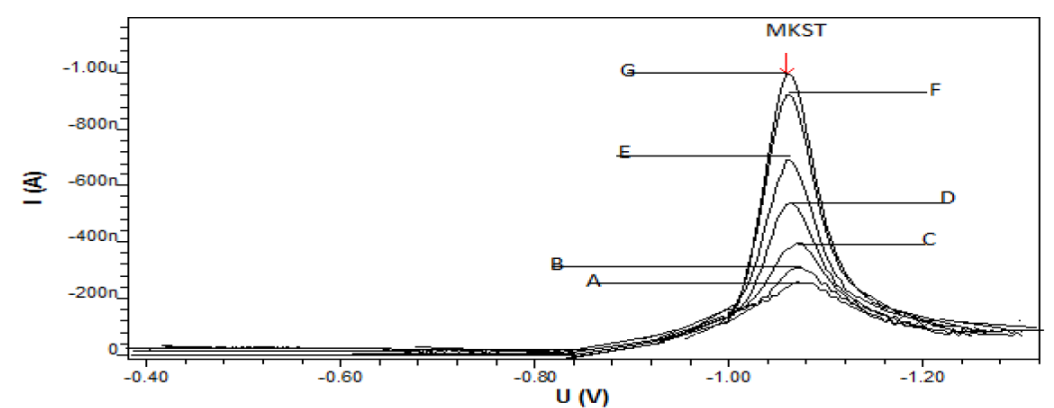

Figure 13. AdSV voltammograms of calibration curve for MKST in B-R buffer $\mathrm{pH}=10, \mathrm{~T}_{\mathrm{acc}}=180 \mathrm{sec}, \mathrm{E}_{\mathrm{acc}}=-0.40 \mathrm{~V}$ and scan rate $=650 \mathrm{mV} / \mathrm{s}$. Drug concentrations: $\left(\mathrm{A}=5 \times 10^{-8} \mathrm{M}, \mathrm{B}=1 \times 10^{-7} \mathrm{M}, \mathrm{C}=2 \times 10^{-7} \mathrm{M}, \mathrm{D}=4 \times 10^{-7} \mathrm{M}, \mathrm{E}=6 \times 10^{-7} \mathrm{M}, \mathrm{F}=8 \times\right.$ $\left.10^{-7} \mathrm{M}, \mathrm{G}=1 \times 10^{-6} \mathrm{M}\right)$.

\section{Precision, accuracy and stability}

The reproducibility of the developed procedure was evaluated from eight repeated measurements of $5 \times 10^{-7} \mathrm{~mol} \mathrm{~L}{ }^{-1} \mathrm{MKST}$. The precision of the method in terms of the relative standard deviation (RSD\%) was $1.1 \%$. The accuracy of the electrochemical method was checked by calculating the recovery of known 
amount $\left(3 \times 10^{-7} \mathrm{~mol} \mathrm{~L}^{-1}\right)$ MKST drug spiked in buffer solution and analysed by the optimised procedure.

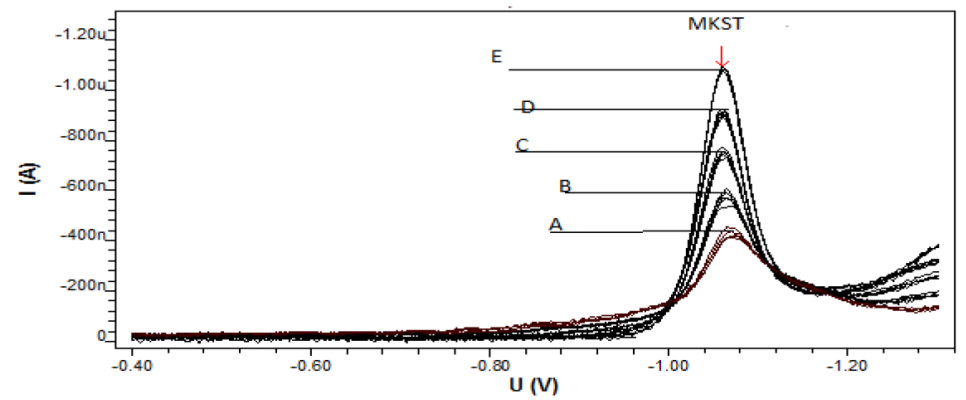

Figure 14. AdSV voltammograms of tablet recovery for MKST in B-R buffer $\mathrm{pH}=10$, $\mathrm{T}_{\mathrm{acc}}=180 \mathrm{sec}, \mathrm{E}_{\mathrm{acc}}=-0.40 \mathrm{~V}$ and scan rate $=650 \mathrm{mV} / \mathrm{s}$. Drug concentrations: $(\mathrm{A}=0 \mathrm{x}$ $\left.10^{-7} \mathrm{M}, \mathrm{B}=2 \times 10^{-7} \mathrm{M}, \mathrm{C}=4 \times 10^{-7} \mathrm{M}, \mathrm{D}=6 \times 10^{-7} \mathrm{M}, \mathrm{E}=8 \times 10^{-7} \mathrm{M}\right)$.

The results of five measurements obtained by the standard addition method have a recovery mean of $102 \%$ with standard deviation of $\pm 2.0 \%$. When the AdSV signal of $5 \times 10^{-} \mathrm{mol} \mathrm{L}^{-1}$ MKST solution was monitored every ten minutes, it was found to nearly stable for a period of 2.0 hours at least.

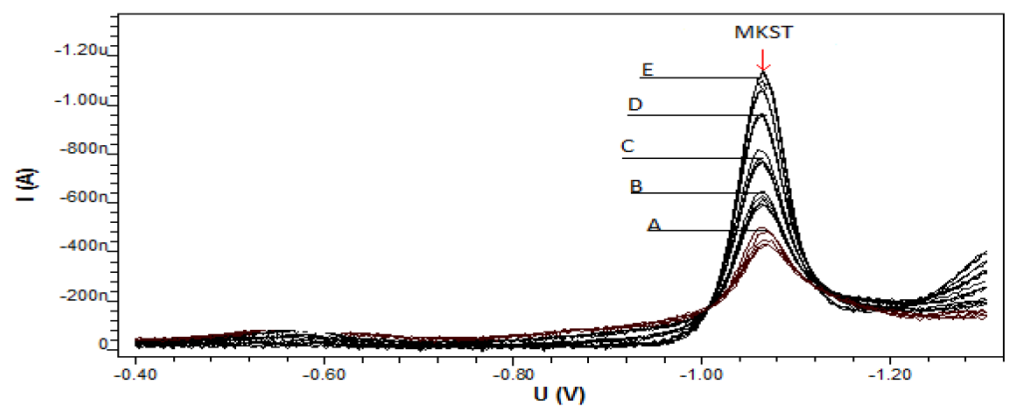

Figure 15. AdSV voltammograms of human urine recovery for MKST in B-R buffer $\mathrm{pH}=10, \mathrm{~T}_{\mathrm{acc}}=180 \mathrm{sec}, \mathrm{E}_{\mathrm{acc}}=-0.40 \mathrm{~V}$ and scan rate $=650 \mathrm{mV} / \mathrm{s}$. Drug concentrations: $\left(\mathrm{A}=0 \times 10^{-7} \mathrm{M}, \mathrm{B}=2 \times 10^{-7} \mathrm{M}, \mathrm{C}=4 \times 10^{-7} \mathrm{M}, \mathrm{D}=6 \times 10^{-7} \mathrm{M}, \mathrm{E}=8 \times 10^{-7} \mathrm{M}\right)$.

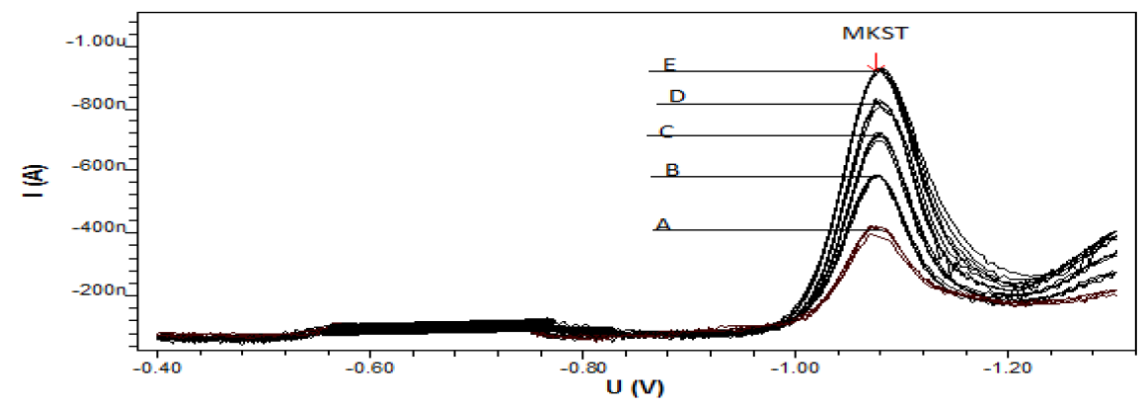

Figure 16. AdSV voltammograms of human plasma recovery for MKST in B-R buffer $\mathrm{pH}=10, \mathrm{~T}_{\mathrm{acc}}=180 \mathrm{sec}, \mathrm{E}_{\mathrm{acc}}=-0.40 \mathrm{~V}$ and scan rate $=650 \mathrm{mV} / \mathrm{s}$. Drug concentrations: $\left(\mathrm{A}=0 \times 10^{-7} \mathrm{M}, \mathrm{B}=2 \times 10^{-7} \mathrm{M}, \mathrm{C}=4 \times 10^{-7} \mathrm{M}, \mathrm{D}=6 \times 10^{-7} \mathrm{M}, \mathrm{E}=8 \times 10^{-7} \mathrm{M}\right)$.

\section{Interferences}

The competitive co-adsorption interference was evaluated in the presence of various substances usually occurring in the pharmaceutical formulation as tablet ingredients or additives. For these investigations, the interfering species (lactose, 
sucrose, glucose and starch) were added in different concentrations (twice, 5 fold and 50 fold) higher than the MKST concentration $\left(5 \times 10^{-7} \mathrm{~mol} \mathrm{~L}^{-1} \mathrm{MKST}\right)$. The addition of 2-fold, 5-fold and 50-fold of lactose, yielded negative interferences by $9.85 \%, 15.3 \%$ and $18.45 \%$, respectively. Also, the addition of 2 -fold, 5 -fold and 50 -fold of glucose, yielded negative interferences by $11.6 \%, 17.8 \%$ and $27.2 \%$, respectively. Furthermore, the addition of twice, 5-fold and 50-fold of starch, yielded negative interferences by $14.7 \%, 20.8 \%$ and $23.8 \%$, respectively. In contrast, the addition of 50-fold of sucrose higher than the quantity of the assayed drug caused the AdSV peak current to decrease by about $7.42 \%$ of its original signal.

This inhibition response is possibly due to the competitive co-adsorption of these interfering substances (particularly at higher concentration levels) on the adsorption sites of HMDE.

Table 1. Determination of MKST in commercial drug by the proposed AdSV method.

\begin{tabular}{|c|c|c|c|}
\hline & & & Reference method [32] \\
\hline & $(m g)$ & Recovery\% & Recovery\% \\
\hline $\begin{array}{l}\text { Labeled content } \\
\text { Singular tablet } \\
10 \mathrm{mg} \mathrm{MKST}\end{array}$ & $\begin{array}{c}10 \\
9.9 \\
9.8 \\
10.2 \\
9.9\end{array}$ & $\begin{array}{r}100 \\
99 \\
98 \\
102 \\
99\end{array}$ & $102.7 \pm 0.9$ \\
\hline & & & \\
\hline
\end{tabular}

Table 2. Determination of MKST in human urine and plasma by the proposed AdSV method.

\begin{tabular}{|c|cc|c|}
\hline \multirow{3}{*}{} & \multicolumn{2}{|c|}{ Proposed method } & Reference method [32] \\
\cline { 2 - 4 } & Spiked urine(\%) & Spiked plasma (\%) & Spiked plasma (\%) \\
\cline { 2 - 4 } & 105 & 100 & 99.2 \\
& 104 & 100 & 105.82 \\
& 102 & 101 & 105.82 \\
Recovery (3x 10-7 & 105 & 102 & 98.74 \\
mol L $^{-1}$ MKST) & 106 & 102 & 100.31 \\
& Mean $=104.4 \%$ & $101 \%$ & Mean $=101.38$ \\
& S.D. $= \pm 1.52$ & \pm 1.0 & S.D. $= \pm 3.85$ \\
\hline
\end{tabular}

\section{Analytical applications}

To assess the reliability of the proposed electrochemical procedure described above, it was applied for resolving the determination of MKST in pharmaceutical preparation. The drug content of the commercially available Singular tablet (Merck Sharp \& Dohme Limited (MSD), Northumberland, UK: contain $10 \mathrm{mg}$ of MKST) was determined via the optimized AdSV procedure directly after the required dissolving and filtration steps and the dissolved sample was diluted to the required concentration level. The electrochemical measurements were done by the standard addition method in order to minimize matrix effects. Five aliquots of this sample were analyzed by the proposed AdSV method (see recovery in Fig. 14). MKST was also determined in urine and plasma via recoveries as shown in Fig. 15 and 16, respectively. The obtained results by 
using the developed AdSV method with regard to determination of MKST in commercial tablet, urine and plasma are given at Tables 1 and 2 .

\section{Acknowledgement}

The author would like to thank Mr. Awad alqarni and Ahmad alribdy at Qassim Pharmaceutical Plant Buraydah, Spimaco Addwaeih, Saudi Arabia for their assistances and supplying us by standard drugs.

\section{References}

1. Kenkel J. Analytical Chemistry for Technicians. $3^{\text {rd }}$. USA:CRC Lewis Publishers;2003.

2. Wang J. Analytical Electrochemistry. New York:VCH Publishers Inc; 1994.

3. Osteryoung J, O`Dea JJ. In: Electroanalytical Chemistry. Vol. 14 (Bard AJ. ed.). New York:Marcel Dekker;1986.

4. Economou A, Filden PR. Anal Chim Acta. 1993;273.27.

5. Zanello P. Inorganic Electrochemistry. Theory, Practice and Application. UK:The Royal Society of Chemistry;2003.

6. Zaitsev PM, Salikhdzhanova RMF, Zaitsev NK. Ind Lab Diag Mater. 1999;65:1.

7. Abu Zuhri AZ, Voelter W. Fresenius J Anal Chem. 1998;360:1.

8. Achterberg EP, Braungardt C. Anal Chim Acta. 1999;400:381.

9. Bento FR, Grassi MT, Sales A, et al. Int J Electrochem Sci. 2008;3:1523.

10. Alghamdi AH. J Saudi Chem Soc. 2010;14:1.

11. Alghamdi AH. Arabian J. Chem. 2010;3:1.

12. Brainina K.H. , Malakhova N.A., Stojko N.Y. Fresenius J Anal Chem. 2000;368:307.

13. Manisankar P, Sundari PA, Sasikumar R. Int J Env Anal Chem. 2009;89:245.

14. Alghamdi AH. J. Saudi Chem Soc. 2002;6:185.

15. Vire JC, Kauffmann JM, Patriarche GJ. J Pharma Biomed Anal. 1989;7:1323.

16. Alghamdi AF, Alghamdi AH, Al-Omar MA. Anal Lett. 2008;41:1.

17. Alghamdi AF, Alghamdi AH, Al-Omar MA. Egypt J Anal Chem. 2008; $17: 98$.

18. Alghamdi AF, Alghamdi AH, Al-Omar MA. Saudi Pharm J. 2008;16:231.

19. Alghamdi AF, Alghamdi AH, Al-Omar MA. J Saudi Chem Soc. 2008;12:1.

20. Alghamdi AF, Alghamdi AH, AlOmar MA. Arabian J Chem. 2008;1:37.

21. Alghamdi AF, Alghamdi AH, Al Omar MA. Port Electrochim Acta. 2009;27:645.

22. Alghamdi J Saudi Chem Soc. 2009;13:235.

23. Alghamdi AF. Am J Anal Chem. $2011 ; 2: 174$.

24. Alghamdi AF, Hefnawy MM. Arabian J Chem. 2012;5:383. 
25. Alghamdi AF, Hefnawy MM, Al-Majed AA, et al. Chem Central J. 2012;6:15.

26. Budhavari S. (Ed). In: The Merck Index. New Jersey:Merck \& Co Inc.;1996. P. 31-315.

27. Budhavari S. (Ed). In: The Merck Index. New Jersey:Merck \& Co Inc.;1999. P. 6337.

28. Prafit K. Ed. In: Martindale, The complete drug reference. $33^{\text {rd }}$ Ed. London:The Pharmaceutical Press;1999. P. 756

29. Morrow JD, Roberts LJ. In: Hardman J. G., Limbrid L. E. (Eds). The Pharmacological Basis of Therapeutics. 10 ${ }^{\text {th }}$ Ed. New York:McGraw Hill;2001. P. 677.

30. Patel DJ, Patel SA, Patel SK. Int J Pharm Biomed Resear. 2010;1:71.

31. Arayne MS, Sultana N, Hussain F. J Anal. Chem. 2009;64:690.

32. Patel S, Pore YV, Kuchecker BS, et al. Indian J Pharm Sci. 2009;71:58.

33. Radhakrishna T, Narasaraju A, Ramakrishna M, et al. J Pharm Biomed Anal. 2003;31:359-368.

34. Alsarra I, Al-Omar M, Gadkariem EA, et al. II Farmaco. 2005;60:563.

35. Stubauer G, Obendorf D. Analyst, 1996;121:351.

36. E Laviron. J Electroanal Chem. 1981;122:37.

37. Wang J. Stripping Analysis, Principles, Instrumentation and Applications. Deerfield Beach, Florida:VCH Publishers, Inc.;1985. 